\title{
Mild sodium reduction in peritoneal dialysis solution improves hypertension in end stage kidney disease: a case-report study
}

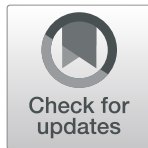

Luigi Vecchi ${ }^{1}$, Mario Bonomini ${ }^{2}$, Roberto Palumbo ${ }^{3}$, Arduino Arduini ${ }^{4}$ and Silvio Borrelli $i^{5^{*}}$ (D)

\begin{abstract}
Introduction: Blood Pressure (BP) control is largely unsatisfied in End Stage Kidney Disease (ESKD) principally due to sodium retention. Peritoneal Dialysis (PD) is the most common type of home dialysis, using a peritoneal membrane to remove sodium, though sodium removal remains challenging.

Methods: This is a case-study reporting two consecutive ESKD patients treated by a novel peritoneal PD solution with a mildly reduced sodium content $(130 \mathrm{mmol} / \mathrm{L})$ to treat hypertension.

Results: In the first case, a 78-year-old woman treated by Continuous Ambulatory PD (CAPD) with standard solution (three $4 \mathrm{~h}$-dwells per day $1.36 \%$ glucose $132 \mathrm{mmol} / \mathrm{L}$ ) showed resistant hypertension confirmed by ambulatory blood pressure monitoring (ABPM), reporting $24 \mathrm{~h}-\mathrm{BP}: 152 / 81 \mathrm{mmHg}$, day-BP:151/83 mmHg and nightABP: 153/75 mmHg, with inversion of the circadian systolic BP rhythm (1.01), despite use of three anti-hypertensives and a diuretic at adequate doses. No sign of hypervolemia was evident. We then switched from standard PD to low-sodium solution in all daily dwells. A six-months low-sodium CAPD enabled us to reduce diurnal (134/75 $\mathrm{mmHg})$ and nocturnal BP $(122 / 67 \mathrm{mmHg})$, restoring the circadian BP rhythm, with no change in ultrafiltration or residual diuresis. Diet and drug prescription were unmodified too.

The second case was a 61-year-old woman in standard CAPD (three $5 \mathrm{~h}$-dwells per day) suffering from hypertension confirmed by ABPM (mean $24 \mathrm{~h}-\mathrm{ABP}: 139 / 84 \mathrm{mmHg}$; mean day-ABP:144/88 mmHg and mean night-ABP:124/70 $\mathrm{mmHg}$ ). She was switched from 132-Na CAPD to 130-Na CAPD, not changing dialysis schedule. No fluid expansion was evident. During low-sodium CAPD, antihypertensive therapy (amlodipine $10 \mathrm{mg}$ and Olmesartan $20 \mathrm{mg}$ ) has been reduced until complete suspension. After 6 months, we repeated ABPM showing a substantial reduction in mean $24 \mathrm{~h}-\mathrm{ABP}(117 / 69 \mathrm{mmHg})$, mean diurnal ABP $(119 / 75 \mathrm{mmHg})$ and mean nocturnal ABP $(111 / 70 \mathrm{mmHg})$. Ultrafiltration and residual diuresis remained unmodified. No side effects were reported in either cases.
\end{abstract}

Conclusions: This case-report study suggests that mild low-sodium CAPD might reduce BP in hypertensive ESKD patients.

Keywords: Low-sodium, Resistant hypertension, Peritoneal Dialysis

\footnotetext{
* Correspondence: dott.silvioborrelli@gmail.com

${ }^{5}$ Department of Advanced Medical and Surgical Sciences, Nephrology Unit of University of Campania "Luigi Vanvitelli", Piazza Miraglia, 80138 Naples, Italy

Full list of author information is available at the end of the article
}

(C) The Author(s). 2021 Open Access This article is licensed under a Creative Commons Attribution 4.0 International License, which permits use, sharing, adaptation, distribution and reproduction in any medium or format, as long as you give appropriate credit to the original author(s) and the source, provide a link to the Creative Commons licence, and indicate if changes were made. The images or other third party material in this article are included in the article's Creative Commons licence, unless indicated otherwise in a credit line to the material. If material is not included in the article's Creative Commons licence and your intended use is not permitted by statutory regulation or exceeds the permitted use, you will need to obtain permission directly from the copyright holder. To view a copy of this licence, visit http://creativecommons.org/licenses/by/4.0/ The Creative Commons Public Domain Dedication waiver (http://creativecommons.org/publicdomain/zero/1.0/) applies to the data made available in this article, unless otherwise stated in a credit line to the data. 


\section{Introduction}

Blood Pressure (BP) control is largely unsatisfied in End Stage Kidney Disease (ESKD) [1, 2]. Poor BP control is principally due to sodium retention leading to extracellular volume (ECV) expansion, which is commonly detectable in ESKD patients [3], significantly worsening the cardio-vascular prognosis of these patients [4]. However, sodium removal remains challenging in dialysis patients.

Peritoneal Dialysis (PD) is the most common type of home dialysis, using a peritoneal membrane to remove sodium and fluid overload [5]. However, in PD sodium removal depends substantially on ultrafiltration, so that an increase in sodium removal needs a high concentration of glucose and/or icodextrin [6]. But hypertonic solutions remove more water than sodium [6] and, furthermore, chronic exposure to glucose load causes local toxicity [7] and metabolic consequences [8]. On the other hand, icodextrin is able to remove sodium, but can only be used once a day with a limited effect on sodium removal by diffusion [9]. Hence, novel strategies are desirable to increase sodium removal and improve BP control.

One therapeutic strategy is lowering the sodium in the PD solution, which may improve sodium removal by diffusion. However, the use of an ultra-low sodium (102$115 \mathrm{mEq} / \mathrm{L}$ ) dialysate commonly leads to hyponatremia, hypotension and diuresis contraction, while these solutions need to be compensated by a hypertonic glucose solution to avoid ultrafiltration (UF) loss [10-14]. More recently, the use of uncompensated PD solutions with a relatively low sodium content $(125 \mathrm{mEq} / \mathrm{L})$ has resulted in an improvement of BP control in PD patients, though there persists a higher risk of hyposodiemia than with a standard PD solution [13, 14].

Our working hypothesis was that a mild, but persistent, reduction in the sodium content of the PD dialysate ( $130 \mathrm{mmol} / \mathrm{L})$ might help to improve BP control, reducing the sodium load in ESKD patients; moreover, this slight reduction in the PD bag sodium content could be better tolerated.

Hence, we used a novel uncompensated glucose 130 mmol Na PD solution to treat two consecutive hypertensive CAPD patients for 6 months, aiming at evaluate its effect on the BP burden.

\section{Case presentation}

\section{Patient n.1}

A 78-year-old woman suffering from End Stage Kidney Disease showed high BP levels resistant to antihypertensive treatment. Written informed consent was obtained from the patient for publication of this case report.

She had a medical history characterized by at least 10 years of poor BP control, despite use of three anti-hypertensives (doxazosin $4 \mathrm{mg}$, amlodipine 10 $\mathrm{mg}$, telmisartan $80 \mathrm{mg}$ ) and a diuretic (furosemide $250 \mathrm{mg}$ ) at the maximum tolerated dose. A low salt diet $(<100 \mathrm{mmol} /$ day $)$ had also been prescribed. Physical examination showed no lower-limb edema or any signs of volume expansion. Ultrasound disclosed that the left kidney was reduced in size, whereas the contralateral kidney showed a high intrarenal resistance index (0.82) suggestive of atherosclerotic reno-vascular disease, with unilateral renal artery stenosis, as the apparent cause of resistant hypertension. The patient refused radiological intervention, so in view of the kidney function deterioration (serum Creatinine: $5.14 \mathrm{mg} / \mathrm{dL}$ estimated GFR by CKD-EPI: $6 \mathrm{~mL} / \mathrm{min} / 1.73 \mathrm{~m}^{2}$ ) and poor BP control, she was put on continuous ambulatory PD (CAPD) using 3 times 2-L exchanges of $1.36 \%$ standard PD solution (Dianeal, Baxter ${ }^{\circ}$ sodium: $132 \mathrm{mmol} /$ L) and an empty abdomen during the nocturnal hours.

After 3 months of CAPD, BP levels persisted elevated (mean Home BP: 152/80 mmHg,), despite euvolemia revealed by echocardiography (collapsibility of inferior vena cava). We therefore performed ABPM (SpaceLabs Healthcare ${ }^{\circ}$ ) to exclude pseudo-resistant hypertension [15]. ABPM yelded poor control of mean 24 h-BP (152/ $81 \mathrm{mmHg})$, mean diurnal $(151 / 83 \mathrm{mmHg})$ and mean nocturnal BP $(153 / 75 \mathrm{mmHg})$, with an inversion of the circadian rhythm (systolic night/day ratio: 1.02). Considering that antihypertensive treatment was still optimal, we switched from standard PD $(132 \mathrm{mEq} / \mathrm{L})$ to a low sodium PD solution using $1.4 \%$ glucose bags with a sodium concentration of $130 \mathrm{mEq} / \mathrm{L}$ (DextroCore LS, Iperboreal Pharma, Italy). The CAPD schedule was confirmed.

As reported in Table 1, over 16 weeks we registered a clinically significant $\mathrm{BP}$ reduction $(-7 \mathrm{mmHg})$ measured by automatic sphygmomanometer (Omron $\mathrm{M}^{\circ}$ ) at home, with no substantial change in body weight, UF, total $\mathrm{Kt} / \mathrm{V}$ or residual diuresis. The patient was trained to use the Omron BP device by medical personnel according to HBP guidelines [16]. Furthermore, no main lab data were modified, while the diet and therapy prescription were unmodified. Peritoneal equilibration test (PET) showed average peritoneal permeability (dialysate/ plasma creatinine ratio:0.76).

After 6 months we performed a second ABPM with mean $24 \mathrm{~h} \mathrm{ABP}$ of $131 / 73 \mathrm{mmHg}$ ), mean diurnal of $134 /$ $75 \mathrm{mmHg}$ and mean nocturnal ABP of $122 / 67 \mathrm{mmHg}$. Notably, the circadian rhythm was restored (systolic night/day ratio: 0.91). Figure 1 (graph at the top named as patient 1) illustrates the difference for each hour between two ABPMs (baseline vs 6 months). Lastly, no side effects were reported. 
Table 1 Description of the main clinical and laboratory features at baseline and after 6 months of 130 mmol Na CAPD

\begin{tabular}{|c|c|c|c|c|}
\hline & \multicolumn{2}{|l|}{ Patient 1} & \multicolumn{2}{|l|}{ Patient 2} \\
\hline & Baseline & 130-Na CAPD & Baseline & 130-Na CAPD \\
\hline Creatinine (mg/dL) & 5.14 & 5.17 & 5.28 & 6.72 \\
\hline Measured GFR (mL/min/1.73 $\left.\mathrm{m}^{2}\right)$ & 6.0 & 6.3 & 9.9 & 6.2 \\
\hline Urine volume (mL/24 h) & 1300 & 1600 & 1700 & 1600 \\
\hline Body weight (kg) & $56.0 \pm 0.4^{a}$ & $56.7 \pm 0.3^{b}$ & $69.0 \pm 0.7^{a}$ & $70.3 \pm 0.6^{b}$ \\
\hline Ultrafiltration (mL/24 h) & $330 \pm 126^{a}$ & $365 \pm 113^{b}$ & $450 \pm 135^{\mathrm{a}}$ & $485 \pm 132^{b}$ \\
\hline Total Ktv & 1.65/week & 1.68/week & 1.75/week & 1.80/week \\
\hline Serum sodium (mmol/L) & 137 & 137 & 138 & 139 \\
\hline Serum potassium (mmol/L) & 4.9 & 4.3 & 4.1 & 3.8 \\
\hline Serum Urea (mg/dL) & 173 & 177 & 144 & 161 \\
\hline Serum Hemoglobin (mg/dL) & 11.6 & 12.4 & 11.5 & 10.4 \\
\hline Serum Albumin (g/L) & 3.3 & 3.6 & 3.9 & 3.5 \\
\hline Serum PTH (pg/mL) & 297 & 250 & 589 & 357 \\
\hline Home Systolic BP (mmHg) & $147 \pm 7^{\mathrm{a}}$ & $140 \pm 9^{b}$ & $135 \pm 5^{\mathrm{a}}$ & $120 \pm 3^{b}$ \\
\hline Home Diastolic BP (mmHg) & $78 \pm 5^{a}$ & $73 \pm 5^{b}$ & $85 \pm 4^{a}$ & $70 \pm 3^{b}$ \\
\hline
\end{tabular}

${ }^{a}$ Mean of all available measurements before the switch $(N=86)$; ${ }^{b}$ Mean of all home measurements after the switch $(N=115)$. All BP measurements were performed by automatic sphygmomanometer (Omron $\mathrm{M3}^{\oplus}$ ). Patients were trained according to EURECA-m, ERA-EDTA and ESH guidelines [16]. Body weight was gauged by automatic scale. Ultrafiltration was calculated by difference in the weight of dialysate before and after each dwell

\section{Patient n.2}

A 69-year-old woman suffering from ESKD started CAPD with three 5-h diurnal dwells with standard PD solution containing $1.36 \%$ glucose and $132 \mathrm{mmol}$ in sodium. After 3 months of standard CAPD, we performed ABPM, finding mean $24 \mathrm{~h}-\mathrm{BP}$ of $152 / 81$ $\mathrm{mmHg}$, mean day-BP of $151 / 83 \mathrm{mmHg}$ and mean night-ABP of $153 / 75 \mathrm{mmHg}$. The patient took calcium-antagonist (amlodipine $10 \mathrm{mg}$ ) and angiotensin II receptor blocker (Olmesartan $20 \mathrm{mg}$ ), with no need of diuretics, because volume expansion was not evident. Based on the previous clinical case, we switched from standard CAPD to $\mathrm{Na} 130 \mathrm{mmol}$ CAPD (1.40\% glucose Dextro-Core LS - Iperboreal Pharma ${ }^{\oplus}$, not changing dialysis schedule. During 6 months of $\mathrm{Na} 130 \mathrm{mmol}$ CAPD, antihypertensive therapy was reduced until the complete suspension, based on BP measurements performed at home [16]. As illustrated in Fig. 1 (graph at the bottom named as patient 2), ABPM showed a substantial reduction in mean $24 \mathrm{~h}$-ABP $(117 / 69 \mathrm{mmHg})$, mean diurnal ABP $(119 / 75 \mathrm{mmHg})$ and mean nocturnal ABP (111/ $70 \mathrm{mmHg}$ ). No change in body weight, ultrafiltration or residual diuresis was found, while the main clinical and lab features were unmodified during follow up (Table 1). No side effects were reported. PET showed an average pattern of peritoneal permeability (Dialisate/plasma creatinine ratio:0.72).

Written informed consent was obtained from the patients for publication of this case report.

\section{Discussion and conclusions}

In the first case report, we describe a significant BP reduction associated with chronic use of low-sodium ( $\mathrm{Na} 130$ mmol), an uncompensated glucose-based PD solution in a female CAPD patient suffering from resistant hypertension. More specifically, we found a significant decrease in systolic ABP $(-16 \mathrm{mmHg})$ after 6 months of PD treatment with Na-130 glucose bags in all daily dwells (three per day), with no substantial change in body weight (BW) or anti-hypertensive therapy, suggesting that BP lowering is the consequence of maintenance treatment by $\mathrm{Na} 130$ mmol PD solution. Considering these findings, we used by this low-sodium CAPD solution on a second hypertensive patient with poor BP control. Similarly, we found substantial BP improvement that allowed us to suspend all antihypertensive drugs. UF, body weight and residual diuresis remained unmodified too.

These findings are consistent with the results of a recent trial comparing uncompensated Na-125 with standard PD solutions, in which a significant improvement was found in systolic BP $(-17 \mathrm{mmHg})$ associated with use of low sodium PD solution in the subgroup of patients with lower GFR $\left(<6 \mathrm{ml} / \mathrm{min} / 1.73 \mathrm{~m}^{2}\right)$, regardless of ultrafiltration [14]. Unlike that previous study [14], we observed that BP control was independent of residual kidney function (RKF) at the baseline $(6.1 \mathrm{ml} / \mathrm{min} /$ $1.73 \mathrm{~m}^{2}$ in the first patient vs $9.9 \mathrm{ml} / \mathrm{min} / 1.73 \mathrm{~m}^{2}$ in the second patient). Furthermore, we noticed a reduction in RKF (from 9.9 to $6.0 \mathrm{ml} / \mathrm{min} / 1.73 \mathrm{~m}^{2}$ ) in the second patient, although no diuresis contraction was found. 


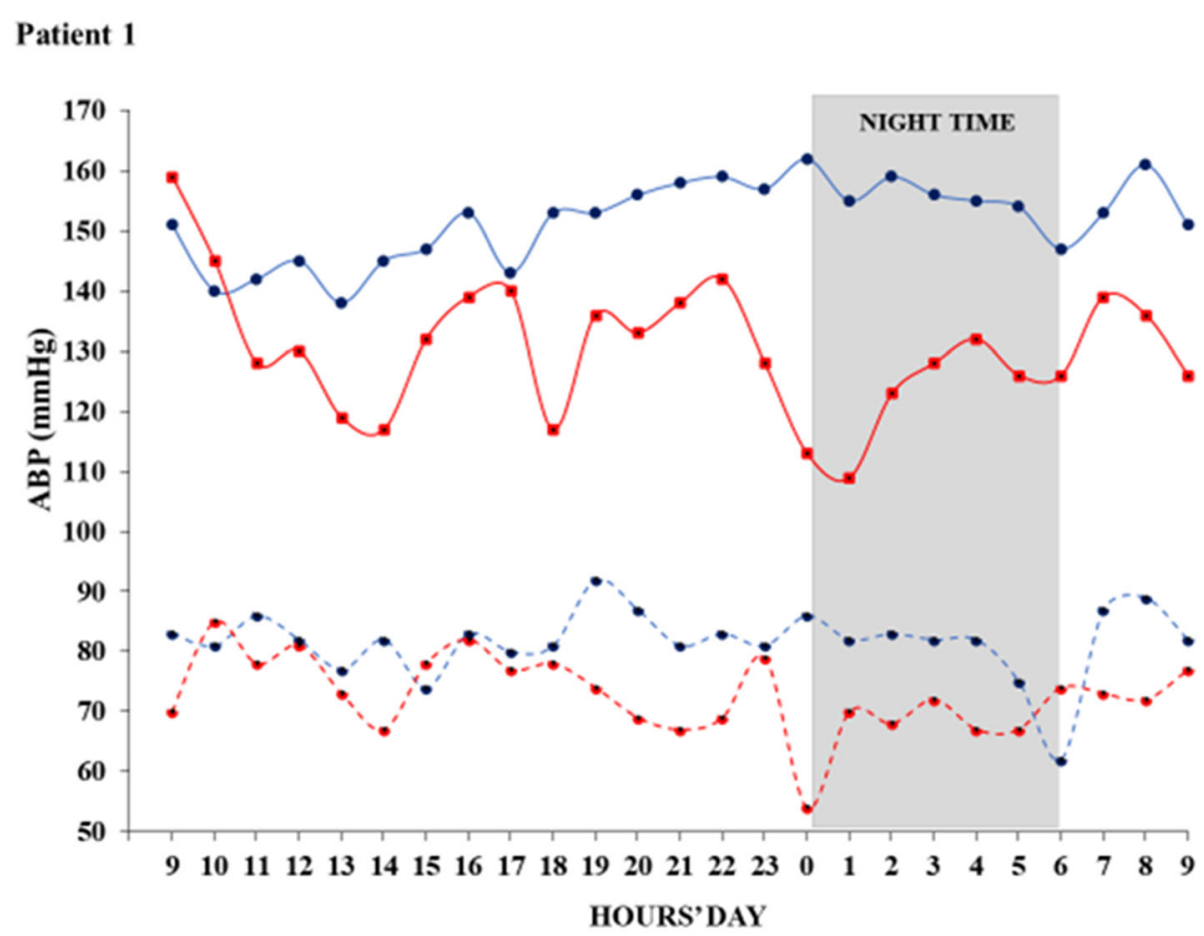

\section{Patient 2}

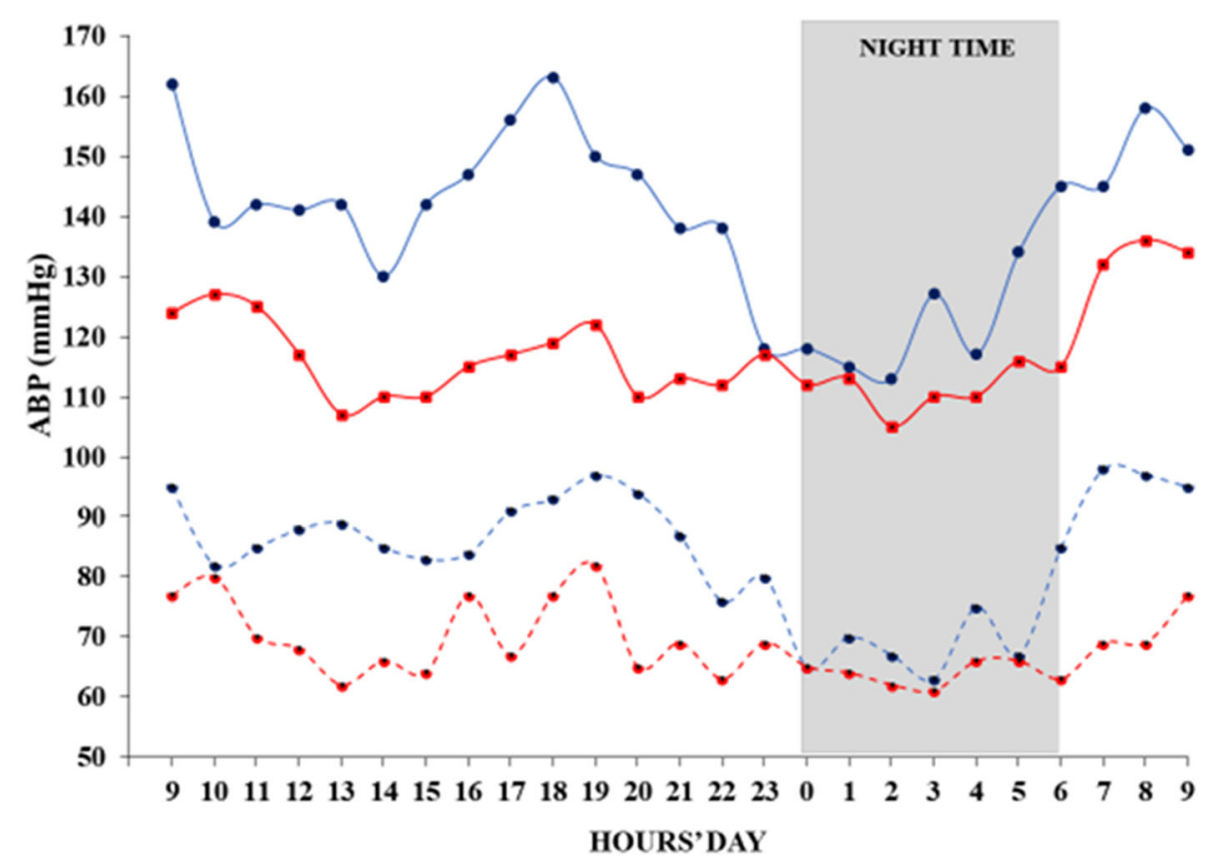

Fig. 1 Systolic (solid line) and Diastolic (dotted line) Ambulatory Blood Pressure at baseline (blue) and after 6 months (red) of Na-130 CAPD in two consecutive hypertensive patients 
Remarkably, the six-months use of $130 \mathrm{mmol} / \mathrm{l} \mathrm{Na}$ CAPD bags was associated with ABP control in both patients, in accordance with recent guidelines recommending an average $\mathrm{BP}<130 / 80 \mathrm{mmHg}$ over 24 -h monitoring in PD patients [16]. ABPMs confirmed the previous findings achieved by Home BP measured during 6-months' follow up (Table 1). More interestingly, we found restoration of the circadian BP rhythm associated with chronic use of Na-130 PD solution in the first case, which may be indirect proof that the effect on our patient's BP rhythm is a direct consequence of sodium lowering throughout the body. For a higher salt intake in salt-sensitive hypertension is associated with an abnormal circadian BP rhythm [17] while sodium correction by low-sodium diet and/or diuretics allows one to improve nocturnal hypertension and restore dipping status $[18,19]$. Similarly, in the second case, optimal BP control with no need of anti-hypertensive therapy in a CKD patient may be further proof of the benefit of CAPD treatment for the sodium body content. Likewise, we may postulate that use of a low-sodium dialysate, improves the sodium overload in total sodium tissue, regardless of the fluid overload.

The latest evidence suggests that sodium may play a pivotal role in salt-sensitive hypertension pathogenesis regardless of the fluid overload. According to a recent hypothesis, sodium is stored in the interstitial tissue by a local mechanism regulated by the mononuclear phagocyte system, which acts as an osmoreceptor by expression of a tonicity enhancer binding protein. This transcription factor leads to VEGF-C production which increases sodium clearance on the part of the lymphatic network, reducing sodium in the skin interstitium. Abnormalities of this local system lead to a salt-sensitive increase in BP [5]. This sodium accumulation in interstitial tissues is currently detectable in humans by ${ }^{23} \mathrm{Na}$ Magnetic Resonance Imaging. Sodium stored in interstitial tissue is higher in CKD [20] and is associated with greater cardiac mass, regardless of volume status [21]. Recent findings suggest that sodium stored in the skin is not unmodifiable, being removable by dialysis [22], thus opening new scenarios for BP treatment of PD patients.

The nature of case-report study prevents us from drawing any causal conclusion, although our findings provide further insights into the use of a low-sodium solution to treat hypertension in PD patients, suggesting that a slight, but continuous, reduction in sodium PD solution is able to improve hypertension, and, unlike using an ultra-low Na solution [10-12], requires no need of compensated solutions at a higher glucose concentration while the risk of hyponatremia and diuresis contraction is limited. Further studies are mandatory to investigate whether the $\mathrm{BP}$ effect was independent of
RKF and whether the loss of RKF may be related to low$\mathrm{Na}$ solution or only the consequence of improved BP control.

Our study has other limitations. First, we did not perform bioimpedance to evaluate fluid volume, since we could not exclude insensible fluid overload. Second, we did not assess sodium balance: although low sodium intake was prescribed in both patients, no information about diet and therapy adherence was available, again, sodium removal was not evaluated.

In conclusion, our case-report study suggests that a slight reduction in the sodium content $(130 \mathrm{mEq} / \mathrm{L})$ of the PD solution, compared to standard PD solutions available in commerce $(132-134 \mathrm{mEq} / \mathrm{L})$, if delivered at all dwells for 6 months, might be enough to improve BP control, probably due to lowering of sodium overload over time. Mild reduction in the sodium content of the PD bag $(130 \mathrm{mmol} / \mathrm{L})$ might be considered as "a right compromise" between the need to reduce the sodium load and avoiding ultrafiltration loss and glucose load. Our findings must necessarily be confirmed by randomized controlled trials aimed at proving the efficacy of such a novel sodium PD solution in hypertensive ESKD patients.

\section{Abbreviations}

ESKD: End stage kidney disease; CAPD: Continuous ambulatory peritoneal dialysis; PD: Peritoneal dialysis; ABPM: Ambulatory blood pressure monitoring; BP: Blood pressure; CKD: Chronic kidney disease; GFR: Glomerular filtration rate; BW: Body weight; UF: Ultrafiltration; VEGF-C: Vascular endothelial growth factor - C; RKF: Residual kidney function

\section{Acknowledgements}

Not Applicable.

\section{Authors' contributions}

Research idea and study design: L.V., S.B., R.P., M.B., A.A.; data acquisition: L.V., R.P., A.A.; data analysis/interpretation: S.B., A.A.; statistical analysis: S.B.; and supervision or mentorship: L.V., R.P., M.B.. Each author contributed important intellectual content during manuscript drafting or revision and accepts accountability for the overall work having ensure that questions pertaining to the accuracy or integrity of the work were appropriately investigated and resolved. All authors read and approved the final manuscript.

\section{Funding}

This research did not receive any grant, funds, fees, and or support.

Availability of data and materials

The information about this study is available contacting corresponding author (SB).

\section{Declarations}

Ethics approval and consent to participate

Published research should comply with guidelines for human studies and should include evidence that the research was conducted ethically in accordance with the World Medical Association Declaration of Helsinki.

Consent for publication

Written informed consent was obtained from the patients for publication of this case report. 


\section{Competing interests}

Dr. Arduino Arduini is the founder and major shareholder of Iperboreal Pharma Srl (Pescara, Italy). The other authors have no competing interests to declare.

\section{Author details}

${ }^{1}$ Unit of Nephrology, Santa Maria Hospital, Terni, Italy. ${ }^{2}$ Department of Medicine, Section of Nephrology and Dialysis, G. d'Annunzio University, Chieti-Pescara, Chieti, Italy. ${ }^{3}$ Unit of Nephrology, Sant'Eugenio Hospital, Rome, Italy. ${ }^{4}$ R\&D Department, Iperboreal Pharma, Pescara, Italy. ${ }^{5}$ Department of Advanced Medical and Surgical Sciences, Nephrology Unit of University of Campania "Luigi Vanvitelli", Piazza Miraglia, 80138 Naples, Italy.

Received: 15 March 2021 Accepted: 29 April 2021

Published online: 08 May 2021

\section{References}

1. Cocchi R, Degli Esposti E, Fabbri A, et al. Prevalence of hypertension in patients on peritoneal dialysis: results of an Italian multicentre study. Nephrol Dial Transplant. 1999;14(6):1536-40. https://doi.org/10.1093/ndt/14. 6.1536

2. Xie X, Lv D, Zheng H, Zhang X, Han F, Chen J. The associations of blood pressure parameters with all-cause and cardiovascular mortality in peritoneal dialysis patients: a cohort study in China. J Hypertens. 2020; 38(11):2252-60. https://doi.org/10.1097/HJH.0000000000002526.

3. van Biesen W, Claes K, Covic A, Fan S, Lichodziejewska-Niemierko M, Schoder $V$, et al. A multicentric, international matched pair analysis of body composition in peritoneal dialysis versus haemodialysis patients. Nephrol Dial Transplant. 2013;28(10):2620-8. https://doi.org/10.1093/ndt/gft296.

4. Zoccali C, Moissl U, Chazot C, Mallamaci F, Tripepi G, Arkossy O, et al. Chronic fluid overload and mortality in ESRD. J Am Soc Nephrol. 2017;28(8): 2491-7. https://doi.org/10.1681/ASN.2016121341.

5. Borrelli S, De Nicola L, Minutolo R, et al. Sodium toxicity in peritoneal dialysis: mechanisms and "solutions". J Nephrol. 2020;33(1):59-68. https:// doi.org/10.1007/s40620-019-00673-4.

6. Borrelli S, La Milia V, De Nicola L, Cabiddu G, Russo R, Provenzano M. Et al; study group peritoneal Dialysis of Italian Society of Nephrology. Sodium removal by peritoneal dialysis: a systematic review and meta-analysis. J Nephrol. 2019;32(2):231-9. https://doi.org/10.1007/s40620-018-0507-1.

7. Schaefer B, Bartosova M, Macher-Goeppinger S, Sallay P, Vörös P, Ranchin B, et al. Neutral $\mathrm{pH}$ and low-glucose degradation product dialysis fluids induce major early alterations of the peritoneal membrane in children on peritoneal dialysis. Kidney Int. 2018;94(2):419-29. https://doi.org/10.1016/j. kint.2018.02.022.

8. Bonomini M, Zammit V, Divino-Filho JC, Davies SJ, Di Liberato L, Arduini A, et al. The osmo-metabolic approach: a novel and tantalizing glucosesparing strategy in peritoneal dialysis. J Nephrol. 2021;34(2):503-19. https:// doi.org/10.1007/s40620-020-00804-2.

9. Frampton JE, Plosker GL. Icodextrin: a review of its use in peritoneal dialysis. Drugs. 2003;63(19):2079-105. https://doi.org/10.2165/00003495-20036319000011.

10. Davies S, Carlsson O, Simonsen O, Johansson AC, Venturoli D, Ledebo I, et al. The effects of low sodium peritoneal dialysis fluids on blood pressure, thirst and volume status. Nephrol Dial Transplant. 2009;24(5):1609-17. https://doi.org/10.1093/ndt/gfn668.

11. Leypoldt JK, Charney DI, Cheung AK, Naprestek CL, Akin BH, Shockley TR. Ultrafiltration and solute kinetics using low sodium peritoneal dialysate. Kidney Int. 1995;48(6):1959-66. https://doi.org/10.1038/ki.1995.497.

12. Davies $S$, Haraldsson B, Vrtovsnik F, Schwenger V, Fan S, Klein A, et al. Single-dwell treatment with a low-sodium solution in hypertensive peritoneal dialysis patients. Perit Dial Int. 2020;40(5):446-54. https://doi.org/1 $0.1177 / 0896860820924136$

13. Rutkowski B, Tam P, van der Sande FM, Vychytil A, Schwenger V, Himmele $R$, et al. Low sodium versus standard-sodium peritoneal dialysis solution in hypertensive patients: a randomized controlled trial. Am J Kidney Dis. 2016; 67(5):753-61. https://doi.org/10.1053/j.ajkd.2015.07.031.

14. Rutkowski B, Tam P, van der Sande FM, Vychytil A, Schwenger V, Himmele $\mathrm{R}$, et al. Residual renal function and effect of low-sodium solution on blood pressure in peritoneal Dialysis patients. Perit Dial Int. 2019;39(4):335-43. https://doi.org/10.3747/pdi.2018.00120.
15. Borrelli S, De Nicola L, Stanzione G, Conte G, Minutolo R. Resistant hypertension in nondialysis chronic kidney disease. Int J Hypertens. 2013; 2013:929183. https://doi.org/10.1155/2013/929183.

16. Sarafidis PA, Persu A, Agarwal $R$, et al. Hypertension in dialysis patients: a consensus document by the European renal and cardiovascular medicine (EURECA-m) working group of the European renal association-European Dialysis and transplant association (ERA-EDTA) and the hypertension and the kidney working group of the European Society of Hypertension (ESH). Nephrol Dial Transplant. 2017;32(4):620-40.

17. Kimura G, Dohi Y, Fukuda M. Salt sensitivity and circadian rhythm of blood pressure: the keys to connect CKD with cardiovascular events. Hypertens Res. 2010;33(6):515-20. https://doi.org/10.1038/hr.2010.47.

18. Uzu T, Ishikawa K, Fujii T, Nakamura S, Inenaga T, Kimura G. Sodium restriction shifts the circadian rhythm of blood pressure from nondipper to dipper in essential hypertension. Circulation. 1997;96(6):1859-62. https://doi. org/10.1161/01.CIR.96.6.1859.

19. Uzu T, Kimura G. Diuretics shift circadian rhythm of blood pressure from nondipper to dipper in essential hypertension. Circulation. 1999;100(15): 1635-8. https://doi.org/10.1161/01.CIR.100.15.1635.

20. Qirjazi E, Salerno FR, Akbari A, Hur L, Penny J, Scholl T, et al. Tissue sodium concentrations in chronic kidney disease and dialysis patients by lower leg sodium-23 magnetic resonance imaging. Nephrol Dial Transplant. 2020: gfaa036. https://doi.org/10.1093/ndt/gfaa036.

21. Schneider MP, Raff U, Kopp C, et al. Skin Sodium concentration correlates with left ventricular hypertrophy in CKD. J Am Soc Nephrol. 2017;28(6): 1867-76. https://doi.org/10.1681/ASN.2016060662.

22. Dahlmann A, Dörfelt K, Eicher F, et al. Magnetic resonance-determined sodium removal from tissue stores in hemodialysis patients. Kidney Int. 2015;87(2):434-41. https://doi.org/10.1038/ki.2014.269.

\section{Publisher's Note}

Springer Nature remains neutral with regard to jurisdictional claims in published maps and institutional affiliations.
Ready to submit your research? Choose BMC and benefit from:

- fast, convenient online submission

- thorough peer review by experienced researchers in your field

- rapid publication on acceptance

- support for research data, including large and complex data types

- gold Open Access which fosters wider collaboration and increased citations

- maximum visibility for your research: over $100 \mathrm{M}$ website views per year

At $\mathrm{BMC}$, research is always in progress.

Learn more biomedcentral.com/submissions 